\title{
Matemática Lúdica na Educação de Jovens e Adultos do Centro de Progressão Penitenciária do Distrito Federal
}

\author{
Recreational Mathematics in Education Adults of the Central Penitentiary \\ Progression of Distrito Federal
}

\author{
Igor dos Santos Lima e Lourival Carlos Cunha Junior \\ Universidade Federal de Goiás \\ igor.matematico@gmail.com \\ Secretaria de Educação do Distrito Federal - SEDF \\ lourivalcarlos@hotmail.com
}

\begin{abstract}
Resumo
Este artigo tem como objetivo mostrar que o uso de truques/jogos matemáticos e algoritmos alternativos para a multiplicação e divisão de números inteiros contribuíram para o aprendizado destas operações. Os atores da pesquisa foram alunos de uma turma de Educação de Jovens e Adultos (EJA), do $2^{\circ}$ Segmento do Centro de Progressão Penitenciária do Distrito Federal (CPP-DF). A análise dos resultados foi feita a partir de questionários respondidos pelos alunos e observações realizadas pelo professor durante as aulas. Os participantes demonstraram empenho, dedicação e interesse em relação aos truques/jogos e aos algoritmos alternativos. Constatamos transformações significativas no rendimento dos alunos. Utilizando os algoritmos egípcio para multiplicação e divisão, obtivemos um aumento de 50\% de acertos na multiplicação e de 59\% na divisão. Além disso, apresentaremos um método novo para realizar multiplicação e divisão de números inteiros, chamado de Método Quinário.
\end{abstract}

Palavras-chave: Algoritmos alternativos, Jogos pedagógicos, Operações entre números inteiros.

\begin{abstract}
This article aims to show that the use of tricks/mathematical games and alternative algorithms for multiplication and Division of whole numbers contributing to the learning of these operations. Research actors were students of a class of adult and youth education (EJA), the $2^{\circ}$ segment of the Central Penitentiary Progression of Distrito Federal (CPP-DF). The analysis of the results was made from questionnaires answered by the students and observations conducted by the teacher during class. The participants demonstrated commitment, dedication and interest in relation to tricks/games and alternative algorithms. We found significant changes in student performance. Using the Egyptian algorithms for multiplication and Division, we have achieved an increase of $50 \%$ of hits on multiplication and $59 \%$ in the division. In addition, we will introduce a new method to perform multiplication and division of integers called Quinary Hine.
\end{abstract}

Keywords: Mathematical tricks, Alternative algorithms, Educational games, Operations between integers. 


\section{Introdução}

No ensino básico é comum os alunos mostrarem dificuldade em aprender os conceitos de Matemática, dentre eles se destacam a multiplicação e divisão entre números inteiros. Percebemos que o maior problema não é identificar qual operação matemática a ser utilizada, mas sim conseguir realizar o algoritmo de forma correta, principalmente o algoritmo da divisão.

O primeiro autor deste artigo trabalha há 12 anos dentro do sistema prisional do Distrito Federal com educação de jovens e adultos, ministrando as disciplinas de Física e Matemática, e percebeu grandes dificuldades dos alunos com as disciplinas de Exatas, principalmente em relação às operações básicas da Matemática. São alunos que tiveram que interromper os estudos por algum tipo de motivo grave. Por exemplo, o envolvimento com drogas e crimes, desestruturação familiar, não conciliação de trabalho e estudos, dentre outros. Muitos deles estão há mais de 15 anos fora de uma sala de aula.

Percebemos que se utilizássemos o método tradicional de ensino de Matemática, apenas adotando aulas expositivas, livros didáticos, apostilas, exercícios propostos, quadro branco, dentre outros recursos tradicionais, nosso objetivo pedagógico de aprendizado não seria alcançado. Pensando nesta situação resolvemos abordar em sala de aula uma forma diferente, divertida e mais simples das operações de multiplicação e divisão de números inteiros, desenvolvida especialmente para esse público.

O trabalho tem com objetivo principal mostrar que podemos utilizar estratégias diferentes das tradicionais, utilizadas na maioria das escolas brasileiras, para ministrar aulas de cativantes de Matemática, mas ao mesmo tempo que sejam eficientes no que se refere à aprendizagem do conteúdo em questão.

Na primeira subseção do item 2 mostraremos algoritmos alternativos para realizar multiplicação e divisão entre números inteiros. Como a multiplicação e divisão egípcia descritos por EVES (2011). Também apresentaremos um método construído pelos autores deste trabalho, chamado de Método de Multiplicação e Divisão Quinária. Este método foi baseado no método egípcio, onde a base utilizada é a base binária. $\mathrm{O}$ método quinário utiliza a base cinco.

Na segunda subseção do item 2 apresentaremos jogos e truques matemáticos com aplicação em soma, subtração e potenciação de números inteiros que podem ser utilizados como ferramenta pedagógica para o ensino de Matemática, a fim de despertar interesse em nossos alunos e tornar as aulas de Matemática mais interessantes e prazerosas.

Na parte de jogos encontram-se os seguintes jogos: jogo de Nim descrito por GRANDO (2000); hex mul- tiplicativo retirado de GUINTHER (2009) e bingo da decomposição de números primos que foi criado pelos autores deste trabalho.

Na parte de truques matemáticos encontram-se os seguintes truques: adivinhar o país, o animal e a cor que a pessoa está pensando; descobrir a peça de dominó adaptado de TORRES (2013); adivinhando a soma de 10 números descritos por SAMPAIO e MALAGUTTI (2006); adivinhação do dia da semana em que a pessoa nasceu adaptado de SÁ (2010); raiz primitiva e adivinhação quinária. Dentre estes truques, os dois últimos foram criados pelos autores deste trabalho e o antepenúltimo é uma adaptação utilizando o inverso multiplicativo de 4 módulo 7.

$\mathrm{Na}$ terceira subseção do item 2, apresentaremos um roteiro dos planos de aula, elaborados pelos autores deste trabalho, para fortalecer os conceitos básicos de multiplicação e divisão de números inteiros positivos. Estes planos de aula utilizaram os algoritmos de multiplicação e divisão egípcia entre números inteiros, jogos e truques matemáticos. Aplicamos estes planos de aulas com alunos da Educação de Jovens e Adultos (EJA) do Sistema Penitenciário do Distrito Federal da unidade do Centro de Progressão Penitenciária (CPP).

No item 3, mostraremos como foram aplicados dois planos de aulas direcionados para multiplicação e divisão de números inteiros positivos. Utilizamos formas alternativas de abordagem desses conteúdos, a fim de melhorar o aprendizado nestas áreas.

Na primeira parte do item 4, iremos analisar o perfil dos alunos que foi realizado este trabalho, são alunos do CPP da EJA. O CPP é um presídio semiaberto, onde a maioria dos alunos trabalham fora durante o dia e voltam à noite para dormir no presídio. Na segunda $\mathrm{e}$ terceira partes, respectivamente, iremos mostrar como foram realizados os planos de aulas sobre multiplicação e divisão entre números inteiros, analisando os resultados obtidos.

No item 5, faremos nossas considerações finais.

\section{Truques/jogos e algoritmos alter- nativos}

Os truques/jogos foram utilizados com alunos da EJA na faixa etária de 20 a 56 anos, mas percebemos que podem ser utilizados com alunos a partir do $6^{\circ}$ do ensino fundamental, ou seja, a partir de 11 anos. $\mathrm{E}$ todas as atividades lúdicas envolvidas neste trabalho têm como um de seus principais propósitos educacionais estimular o ensino e aprendizagem de multiplicação e divisão de números inteiros, fixando os conteúdos e tornando as aulas de Matemática mais atrativas para os perfis de alunos do sistema prisional envolvidos. 


\subsection{Formas alternativas para realizar multi- plicações de números inteiros}

\subsubsection{Multiplicações no Egito}

Vamos utilizar um exemplo de multiplicação retirado de EVES (2011), do produto de 26 por 33 . Como $26=$ $16+8+2$, basta somarmos os múltiplos correspondentes de 33. O trabalho pode ser disposto como se segue:

\begin{tabular}{|l|l|}
\hline 1 & 33 \\
\hline$\cdot 2$ & 66 \\
\hline 4 & 132 \\
\hline$" 8$ & 264 \\
\hline$" 16$ & 528 \\
\hline
\end{tabular}

Figura 1: Multiplicação egípcia: 26 por 33.

Somando-se os múltiplos adequados de 33 na segunda coluna, isto é, aqueles indicados com asterisco na primeira coluna, chega-se a resposta 858 .

Os egípcios usavam uma técnica bem simples baseada na duplicação de números naturais, bastava que a pessoa soubesse encontrar o dobro de um número.

\subsubsection{Divisões no Egito}

A divisão era feita usando o mesmo processo da multiplicação, mas em sentido inverso. Vejamos um exemplo retirado de EVES (2011) para dividir 753 por 26. Dobramos sucessivamente o divisor 26 até o ponto em que o próximo dobro exceda o dividendo 753 . O procedimento está exposto na figura 2.

\begin{tabular}{|l|l|}
\hline 1 & 26 \\
\hline 2 & 52 \\
\hline $4^{*}$ & 104 \\
\hline $8^{*}$ & 208 \\
\hline $16^{*}$ & 416 \\
\hline
\end{tabular}

Figura 2: Divisão egípcia: 753 por 26.

Como

$$
\begin{gathered}
753=416+337 \\
753=416+208+129 \\
753=416+208+104+25 .
\end{gathered}
$$

Portanto, observando as linhas com asteriscos na primeira coluna acima, logo o quociente da divisão é $16+$ $8+4=28$ e o resto é 25 .

\subsubsection{Multiplicação quinária}

Mostraremos a seguir um método não encontrado em nossa pesquisa bibliográfica, que denominamos multiplicação quinária. Utilizaremos apenas multiplicações e divisões até o algarismo cinco para realizar qualquer multiplicação de números inteiros positivos. Ele é uma alternativa para fugirmos do nosso algoritmo tradicional e mostrar que existem outras possibilidades para realizar multiplicações.

Primeiramente, apresentaremos duas técnicas para facilitar estes cálculos. Para multiplicar um número por 5, basta multiplicar ele por 10 e posteriormente obter a metade. Para dividir um número por 5 basta agora fazer o contrário, ou seja, multiplicar por 2 e dividir por 10.

$\mathrm{O}$ algoritmo consiste em construir uma tabela com quatro colunas colocando um dos fatores na primeira coluna e o outro na segunda, a terceira coluna vai servir para colocar os restos, e na quarta a multiplicação do resto (R) pelo número que está à sua esquerda, que chamaremos de B, veja a figura 3. Vamos exemplificar

\begin{tabular}{|c|c|c|c|}
\hline$A$ & $B$ & Resto $R$ da divisão de $A$ por $B$ & $B \cdot R$ \\
\hline 326 & 924 & 1 & 924 \\
\hline 65 & 4620 & 0 & 0 \\
\hline 13 & 23100 & 3 & 69300 \\
\hline 2 & 115500 & 2 & 231000 \\
\hline 0 & & Produto & 301224 \\
\hline
\end{tabular}
os passos a serem tomados, utilizando a multiplicação de 326 por 924 .

Figura 3: Método quinário, multiplicação de 326 por 924.

1- Escrevemos 326 na primeira linha da primeira coluna e o 924 na primeira linha da segunda coluna.

2- Dividimos 326 por 5, logo temos como quociente 65 e resto 1 , colocamos 65 abaixo do 326 e o 1 na coluna do resto. Dividimos 65 por 5, encontramos quociente 13 e resto 0 , colocamos 13 abaixo do 65 e o 0 na coluna dos restos. Dividimos 13 por 5 encontramos quociente 2 e resto 3, colocamos 2 abaixo do 13 e o 3 na coluna dos restos. Dividimos 2 por 5 , encontramos quociente $0 \mathrm{e}$ resto 2, colocamos o quociente 0 abaixo do 3 e o resto 2 na coluna dos restos. Como chegamos ao quociente 0 encerramos este procedimento.

Enquanto os números da primeira coluna são divididos por 5, os números da segunda coluna serão multiplicados por 5, até que seja preenchida a tabela, ou seja, a terceira coluna seja preenchida até emparelhar com o último resto.

3- Multiplicamos 924 por 5 e colocamos o resultado (4620) abaixo do 924. Multiplicamos 4620 por 5 e colocamos o resultado (23100) abaixo do 4620. Multiplicamos 23100 por 5 e colocamos o resultado (115500) abaixo do 23100.

4- Multiplicamos o resto R por B, ou seja, multiplicamos o elemento da segunda coluna com seu respectivo resto, que está na terceira coluna e colocamos o resultado na quarta coluna. 
5- Agora somamos todos os elementos da quarta coluna e chegamos ao resultado da multiplicação de 326 por 924 .

A explicação para este algoritmo é que todo número natural escreve-se como soma de potências de 5. Logo para efetuar a multiplicação de 326 por 924, escrevemos 326 na base cinco:

$$
326=2 \cdot 5^{3}+3 \cdot 5^{2}+0 \cdot 5^{1}+1 \cdot 5^{0},
$$

$\log$,

$$
\begin{gathered}
326 \cdot 924=\left(2 \cdot 5^{3}+3 \cdot 5^{2}+0 \cdot 5^{1}+1 \cdot 5^{0}\right) \cdot 924 \\
=\left(2 \cdot 5^{3}+3 \cdot 5^{2}+1 \cdot 5^{0}\right) \cdot 924 \\
=(250+75+1) \cdot 924=231000+69300+924=301224 .
\end{gathered}
$$

\subsubsection{Divisão quinária}

Mostraremos a seguir um método não encontrado em nossa pesquisa bibliográfica, que denominamos divisão quinária, um algoritmo alternativo para realizar divisões de números inteiros, utilizando novamente a base 5 . É suficiente que o aluno saiba somar, subtrair e multiplicar por 5.

Para ilustrar, realizamos a divisão de 225 por 8 .

Preenchemos a primeira coluna obrigatoriamente com o número 1 e a segunda coluna sempre com o divisor, no caso o 8. Em seguida, multiplicaremos por 5 os valores das duas colunas, até que o último valor da segunda coluna seja menor ou igual a 225 , conforme a figura 4 .

\begin{tabular}{|l|l|}
\hline 1 & 8 \\
\hline 5 & 40 \\
\hline 25 & 200 \\
\hline
\end{tabular}

Figura 4: Divisão quinária: 225 por 8.

Como o resultado da próxima multiplicação por 5 é $1000=200 \cdot 5$, e é maior que 225 , paramos. Segue que

$$
\begin{gathered}
225=200+25 \\
225=200+8+17 \\
225=200+8+8+9 \\
225=200+8+8+8+1 .
\end{gathered}
$$

Em relação a primeira coluna, como o 200 corresponde ao 25 e 8 corresponde ao $1, \log$ o o quociente da divisão é $25+1+1+1=28$ e o resto é 1 .

\subsection{Jogos e truques matemáticos}

\subsubsection{Jogo do Nim}

Existem várias versões do jogo do Nim. Vamos mostrar uma versão do jogo adaptado de GRANDO (2000), que é mais fácil de explicar a estratégia de vencer aos alunos, pois esta estratégia é baseada em restos de divisão entre dois números inteiros.

Nesta versão temos apenas um grupo de palitos. Em cada jogada podemos retirar quantidades de palitos variando de 1 a 4 , alternando as jogadas, perde quem retirar o último palito. Vamos utilizar duas jogadoras fictícias para exemplificar o jogo, Annelise e Ariadna.

$\mathrm{O}$ jogo se inicia com 18 palitos. Annelise começa o jogo retirando 2 palitos, deixando 16 no monte. Ariadna joga e retira 3 palitos, deixando 13 no monte. Annelise joga e retira 2 palitos deixando 11 no monte. Ariadna joga e retira 4 palitos deixando 7 no monte. Annelise joga e retira 1 palito, deixando 6 no monte. Neste ponto percebemos que a Ariadna não tem mais chance, pois para qualquer quantidade que ela tirar, de 1 até 4 , Annelise jogará deixando apenas um palito no monte para ser retirado por Ariadna, portanto, Annelise vencerá o jogo.

A estratégia de vencer o jogo está baseada na divisão euclidiana de números inteiros. Segundo HEFEZ (2013) a divisão euclidiana, ou divisão com restos, é uma das quatro operações que toda criança aprende na escola. Sua formulação precisa é:

Teorema 1 (Divisão Euclidiana). Sejam a e $b$ dois números inteiros com $b \neq 0$. Existem dois únicos números inteiros $q e$ $r$ tais que $a=b q+r$, com $0 \leq r \leq|b-1|$, onde q é chamado de quociente e $r$ de resto da divisão de a por $b$.

Para deixar o enunciado mais claro, apliquemos ao jogo. Como a regra do jogo é retirar palitos de 1 até 4 , realizemos a divisão euclidiana por 5 , ou seja, dividindo 18 por 5 , temos quociente 3 e resto 3 , já que $18=3 \cdot 5+$ 3. Annelise pode pensar somente no resto da divisão, que é 3, como se fosse sua última jogada, retirando 2 e deixando 1 para Ariadna retirar, ou seja $16=3$. $5+1$. Para qualquer jogada de Ariadna, a quantidade de palitos deixados no monte, quando divididos por 5 , não deixa resto 1 , pois só pode retirar de 1 até 4 palitos. Dessa forma, se Annelise seguir a estratégia, com certeza ela ganhará o jogo. E foi isso que ela fez. Como Ariadna retirou 3 palitos, deixando 13 e $13=2$. $5+3$, na jogada seguinte Annelise retirou 2, para deixar 11 que é da forma $11=2 \cdot 5+1$, e assim sucessivamente caminhando para vitória.

Este jogo despertou muito interesse nos alunos, principalmente quando eles conheceram as estratégias, e os vencedores foram os que conseguiram encontrar o resto da divisão por 5 com mais facilidade. Utilizamos 
como motivador nas aulas de divisão e de critérios de divisibilidade.

Percebemos que podemos adotar outras regras com o mesmo jogo. Como por exemplo: o jogador pode tirar quantidades de palitos de 1 até 6 palitos em cada jogada, $\operatorname{logo}$ a divisão euclidiana será por 7 , ou seja, temos que analisar o resto da divisão por 7 .

\subsubsection{Hex Multiplicativo}

Vamos exemplificar o jogo retirado de GUINTHER (2009). Veja o tabuleiro do jogo na figura 5 a seguir.

\begin{tabular}{lllllllllll}
\multicolumn{10}{c}{ NÚMIE RO S EMJOGO } \\
\hline 11 & & 31 & & 51 & & 71 & & 91 \\
\hline & 21 & & 41 & & 61 & & 81 &
\end{tabular}

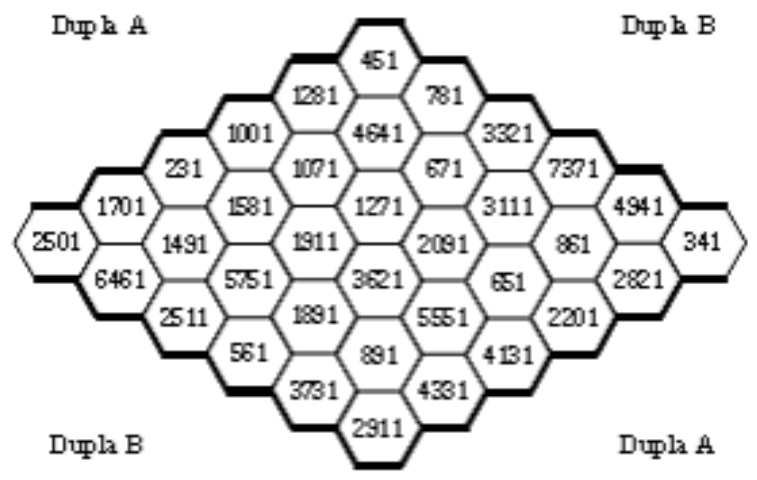

Figura 5: Tabuleiro do jogo Hex multiplicativo.

Os jogadores decidem no "par ou ímpar" quem irá começar o jogo. Jogando alternadamente, em cada rodada, a dupla escolhe dois números do topo do tabuleiro e encontram seu produto. Por exemplo: escolhendo 31 e 11, cujo produto é 341 . Se 341 estiver em uma casa do tabuleiro que não esteja já marcada, coloca um de seus marcadores nessa casa (lembrando que os adversários tem que ter marcadores diferentes para não confundirem as marcações). Se a casa já estiver marcada, a dupla perde a vez de jogar. Em cada casa pode-se colocar apenas um marcador. Ganha a dupla que primeiro conseguir ligar suas duas bordas do tabuleiro com seus marcadores, sem que haja nenhuma marca do adversário no caminho.

Percebemos que neste jogo trabalha-se a operação da multiplicação, exigindo concentração e boas estratégias das duplas na escolha dos dois números para encontrar seu produto, a fim de que consiga chegar ao outro lado com a menor quantidade de jogadas.

\subsubsection{Bingo da decomposição em primos}

Sabemos que todo número inteiro maior que 1 pode ser escrito de forma única como produto de potências de números primos, isto é o que diz o Teorema Fundamental da Aritmética. Segundo HEFEZ (2013), este resultado, porém, não explicitamente enunciado em sua totalidade, está essencialmente contido em Os Elementos (tratado matemático e geométrico consistindo de 13 livros organizados pelo matemático grego Euclides em Alexandria), pois ele é consequência quase imediata de proposições que lá se encontram. Baseado nesta afirmação demonstrada por Euclides, vamos apresentar um jogo que criamos e chamaremos de bingo da decomposição em primos. Ele consiste em um jogo de bingo normal, a única diferença é que os números nas cartelas estão na forma fatorada.

Para exemplificar o jogo utilizamos pedras numeradas de 2 até 30 . Retiramos o número 1 de forma proposital, a fim de mostrar que o 1 é um número que tem uma característica que o separa dos outros números naturais, ou seja, o número 1 não é primo e nem composto. Para tal utilizamos cartelas com dez números em sua forma fatorada, conforme figura 6 .

\begin{tabular}{|c|c|c|c|c|}
\hline 2 & 7 & $2 \cdot 5$ & 13 & $2 \cdot 2 \cdot 2 \cdot 2$ \\
\hline $2 \cdot 3$ & $3 \cdot 3$ & $2 \cdot 2 \cdot 3$ & $2 \cdot 7$ & $3 \cdot 7$ \\
\hline
\end{tabular}

Figura 6: Exemplo de cartela para bingo da decomposição em primos.

Distribuímos uma cartela para cada aluno ou dupla, ou grupos, da maneira que o professor achar melhor, juntamente com feijões ou milhos para que os alunos possam marcar os números sorteados que constam em suas cartelas. Confeccionamos uma cartela especial com os números de 2 até 30 para o professor controlar as pedras que forem sorteadas.

Os números de 2 a 30 serão escritos em um papel, dobrados e colocados em um saco. O professor inicia o jogo retirando um número de cada vez e lendo-o para os alunos. Os alunos realizam a fatoração do número sorteado e caso a fatoração se encontra em sua cartela, marcá-la. Exemplo: o professor retira o número 14 e lê para os alunos, logo os alunos que tiverem $2 \cdot 7 \mathrm{em}$ sua cartela devem marcá-lo. Ganha aquele que preencher toda cartela primeiro. Caso alguém anuncie que ganhou, o professor deve verificar se todos os números que foram sorteados constam na cartela do suposto ganhador.

Este jogo tem como objetivo mostrar o Teorema Fundamental da Aritmética, aplicando-o na construção do conjunto dos números inteiros utilizando a operação 
de multiplicação. E ainda, reforçando o conceito de números primos e compostos, mostrando que todos os números inteiros podem ser construídos a partir de números bases, que chamamos de primos.

\subsubsection{Adivinhar o país, o animal e a cor que a pessoa está pensando}

Este truque é baseado no critério de divisibilidade de um número por 9 , mas também aborda as 4 operações fundamentais da aritmética. O mágico fára um truque através de um número escolhido de 1 a 10. Seu procedimento é o seguinte:

1- Escolha um aluno e peça que ele pense em um número de 1 até 10 .

2- Multiplique o número escolhido por 9.

3- Se o número obtido tiver 2 algarismos, some os seus dois algarismos. Caso contrário, o conserve-o.

4- Some 11 ao resultado obtido.

5- Divida por 5 o resultado obtido.

6- Agora você ira relacionar o número obtido com as letras do alfabeto da seguinte forma: se for 1 é a letra A; se for 2 é a letra B; se for 3 é a letra C; e assim por diante.

7- Pense em um país que comece com esta letra.

8- Com a quinta letra da escrita do nome desse país, pense em um animal e uma cor que comece tal letra.

Depois da realização destes procedimentos, o professor fala para o aluno que ele pensou na Dinamarca, no macaco e na cor marrom.

O segredo da mágica é que em todo número cuja soma dos algarismos é divisível por 9, o número também o é.

O mágico pediu para multiplicar o número pensado por nove e somar seus dois algarismos. Sabemos que a soma de todos os números de dois algarismos múltiplos de nove é 9, portanto, daí em diante o resultado é previsível. Ao somar 11 ao resultado e dividir por 5 terá como resultado final 4. Portanto, qualquer número que a pessoa pense o resultado final vai ser 4 . Relacionando o número com a letra, temos que 4 corresponde a letra D. O país mais conhecido que começa com a letra $D$ é a Dinamarca, existe dois outros, mas é quase certo a pessoa não irá lembrar deles: Djibouti, na África, e Dominica, na América Central. Olhando para quinta letra do país, que será a previsível letra $\mathrm{M}$, o mágico diz para pessoa pensar em um animal e uma cor. Porém o animal mais fácil de lembrar com a letra m é o macaco e a cor é a marrom.

Esta mágica pode ser estendida, pedindo o que a pessoa pense em qualquer número e multiplique por 9 , e some seus algarismos, se a soma for maior que 10 some novamente, e assim por diante até que a soma seja menor que 10. Exemplo, penso no número 32, multiplicando por 9, dá 288. Como 288 é maior que 10, some seus algarismos, o resultado é 18. Como 18 é maior que 10, some novamente, cujo resultado é o 9 , que é o esperado.

\subsubsection{Descobrir a peça de dominó}

Este truque consiste em descobrir a peça de dominó que a pessoa está pensando. Este jogo estimula o cálculo mental das 4 operações fundamentais da Matemática, pois a pessoa que escolhe a peça tem que realizá-las de forma correta para que o mágico não erre a peça escolhida. Esta mágica pode ser realizada com ou sem o dominó.

Vamos exemplificar esta mágica baseado em TORRES (2013).

1- O mágico pede a uma pessoa que pense ou retire uma peça de dominó, sem revelá-la.

2- Em seguida a pessoa deve realizar os seguintes cálculos com os números da peça sem fazer nenhum comentário sobre os resultados: escolher um dos números presentes na peça, qualquer um, e multiplicar por 2; ao resultado somar 4; multiplicar por 5 o número obtido; finalmente adicionar o valor obtido com o outro número da peça.

3- A pessoa revela o resultado das operações ao mágico e o ele descobre a peça pensada pela pessoa.

O mágico apenas subtraiu 20 do número revelado pela pessoa, este número tem 2 algarismos, que representa a peça escolhida.

Vamos dar uma explicação para esta mágica apenas utilizando raciocínio lógico. Sejam $\mathrm{X}$ e $\mathrm{Y}$ os números que representam a peça escolhida, logo a expressão matemática que representa as operações é a seguinte:

$$
(2 \cdot X+4) \cdot 5+Y=10 \cdot X+20+Y=X Y+20 .
$$

Olhando para equação desta forma, basta retirarmos 20 do resultado que temos a peça escolhida pela pessoa, onde um dos lados da pedra é o algarismo da unidade e o outro é o algarismo das dezenas.

Além de podermos trabalhar o cálculo mental, é uma oportunidade abordarmos a propriedade distributiva da multiplicação em relação à soma e subtração, e também discutir o sistema decimal posicional, que utilizamos hoje em dia. Esta mágica estará em nosso plano de aula sobre multiplicação de números inteiros.

\subsubsection{Adivinhando a soma de 10 números}

Aqui vamos mostrar um truque cujo seu segredo está em uma propriedade da sequência de Fibonacci. Este truque consiste em adivinhar a soma de dez números.

Este truque foi baseado em SAMPAIO e MALAGUTTI (2006), com algumas adaptações. Ele consiste em pedir a uma pessoa que pense em dois números inteiros, de 1 até 10, para serem os dois primeiros número de uma sequência de Fibonacci, e escreva mais 8 números 
desta sequência (lembrando que o próximo número de uma sequência de Fibonacci é gerado pela soma dos dois números anteriores). Por exemplo, a pessoa pensa e escreve 2 e 7 , logo o terceiro é $2+7=9$, o quarto é $7+9=16$, o quinto é $9+16=25$, e assim por diante, conforme a figura 7 .

\begin{tabular}{|l|l|}
\hline $1^{\circ}$ & 2 \\
\hline $2^{\circ}$ & 7 \\
\hline $3^{\circ}$ & 9 \\
\hline $4^{\circ}$ & 16 \\
\hline $5^{\circ}$ & 25 \\
\hline $6^{\circ}$ & 41 \\
\hline $7^{\circ}$ & 66 \\
\hline $8^{\circ}$ & 107 \\
\hline $9^{\circ}$ & 173 \\
\hline $10^{\circ}$ & 280 \\
\hline
\end{tabular}

Figura 7: 10 primeiros números de uma sequência de Fibonacci, começando com 2 e 7.

Agora a pessoa mostra a sequência rapidamente ao mágico, que instantaneamente diz o resultado da soma dos 10 números gerados por esta sequência, no caso 726 .

O segredo desta mágica é simples, basta pegar o $7^{\circ}$ número da sequência e multiplicar por 11, assim, nós encontramos o resultado da soma dos 10 primeiros números desta sequência. Multiplicar por 11 é fácil, se o número tem dois algarismos, é suficiente somar seus dois dígitos e colocar entre os dois algarismos originais, fazendo a mudança de valor posicional, se necessário. Vamos utilizar a mágica para melhor explicar. Multiplicar o $7^{\circ}$ termo por 11 , que neste caso é 66 , basta somar $6+6=12$, como $12>9$, retira 10 de 12 e passa 1 para casa da centena, somando com o seis do lado esquerdo, dessa forma:

$$
66 \cdot 11=“ 6126 ”=726 .
$$

Demonstraremos por Recorrência que a soma dos 10 primeiros números de uma sequência de Fibonacci é 11 vezes o $7^{\circ}$ termo.

Sejam $a_{j}, 1 \leq j \leq 10$, os 10 primeiros termos dessa sequência. Como ela é gerada pela soma dos dois termos anteriores, temos:

$$
\begin{gathered}
a_{1}+a_{2}+a_{3}+a_{4}+a_{5}+a_{6}+a_{7}+a_{8}+a_{9}+a_{10} \\
=\left(a_{1}\right)+\left(a_{2}\right)+\left(a_{1}+a_{2}\right)+\left(a_{1}+2 a_{2}\right)
\end{gathered}
$$

$$
\begin{gathered}
+\left(2 a_{1}+3 a_{2}\right)+\left(3 a_{1}+5 a_{2}\right)+\left(5 a_{1}+8 a_{2}\right) \\
+\left(8 a_{1}+13 a_{2}\right)+\left(13 a_{1}+21 a_{2}\right)+\left(21 a_{1}+34 a_{2}\right) \\
=\left(55 a_{1}+88 a_{2}\right)=11\left(5 a_{1}+8 a_{2}\right)=11 \cdot a_{7} .
\end{gathered}
$$

\subsubsection{Adivinhação do dia da semana em que a pessoa nasceu}

Este truque é muito interessante, pois parece ser impossível uma pessoa decorar todos os calendários de mais de 100 anos atrás. No entanto, se utilizarmos os cálculos matemáticos teremos em posse um calendário de 200 anos. O truque consiste em perguntar a uma pessoa em que dia, mês e ano que ela nasceu. Com essas informações o mágico revela o dia da semana em que a pessoa nasceu.

Vamos utilizar o procedimento adaptado de SÁ (2010), utilizando congruência e que o número 2 é inverso multiplicativo de 4 módulo 7 . Este método funciona para datas entre 1900 e 2099, devido à particularidade dos anos 1900 e 2100 que não são bissextos, pois são múltiplos de 4, mas são seculares e não são múltiplos de 400.

Por causa dos sete dias da semana, o algoritmo adaptado consiste em fazer congruências módulo 7 do dia de nascimento X e de quantos anos se passaram desde 1900 até o ano em que a pessoa nasceu, chamamos esta quantidade de Y. Em seguida, analisamos quantos dias 29 de fevereiro se passaram até a data de nascimento. Para isso, consideramos divisão por 4 , sem considerar o resto, denotando o quociente dessa divisão por Z (essa parte pode ser substituída por: encontramos o múltiplo de 4 mais próximo, por falta, da diferença do ano do evento e 1900. Em seguida, a partir resultado encontrado, achamos o resto da divisão por sete e multiplicamos por dois). $\mathrm{O}$ mês de nascimento é associado a um número $\mathrm{W}$ via tabela na figura 8 . Por fim, o resultado $\mathrm{R}$ é o obtido fazendo-se a soma $\mathrm{X}+\mathrm{Y}+\mathrm{Z}+\mathrm{W}$ módulo 7 e verificando o dia da semana que corresponde a $\mathrm{R}$ na tabela da figura 9.

Consideramos uma data de 16 de março de 2009, logo fazemos $16 \equiv 2(\bmod 7)$, março está relacionado com o número 3 (conforme figura 8$), 109 \equiv 4(\bmod 7)$, como 108 é o múltiplo de 4 mais próximo de 109 por falta, segue que $108 \equiv 3(\bmod 7)$ e $2 \cdot 3=6, \operatorname{logo} 2+3+4+6 \equiv$ $1(\bmod 7)$. Portanto, é uma segunda-feira (conforme figura 9).

Caso a data do evento seja até 29 de fevereiro de um ano bissexto, devemos retirar 1 do resultado final, pois 29 de fevereiro ainda não passou. 


\begin{tabular}{|l|l|l|l|}
\hline Janeiro & 0 & Julho & 6 \\
\hline Fevereiro & 3 & Agosto & 2 \\
\hline Março & 3 & Setembro & 5 \\
\hline Abril & 6 & Outubro & 0 \\
\hline Maio & 1 & Novembro & 3 \\
\hline Junho & 4 & Dezembro & 5 \\
\hline
\end{tabular}

Figura 8: Relaciona o mês com um número para realizar adivinhação do dia da semana.

\begin{tabular}{|l|l|}
\hline Segunda & 1 \\
\hline Terça & 2 \\
\hline Quarta & 3 \\
\hline Quinta & 4 \\
\hline Sexta & 5 \\
\hline Sábado & 0 \\
\hline Domingo & 0 \\
\hline
\end{tabular}

Figura 9: Relaciona o número com o dia da semana para realizar adivinhação do dia da semana.

\subsubsection{Raiz primitiva}

O truque consiste em pedir a uma pessoa, com auxílio de uma calculadora, que encontre qualquer potência de dois que desejar, ou seja, com auxílio da calculadora multiplique quantos 2 quiser, $2 \cdot 2 \cdot \ldots \cdot 2$. Informando o resto da divisão do número obtido por 5 e quantidade de algarismos que ele possui ao mágico. Com estas informações o mágico revela o número desconhecido. $\mathrm{O}$ segredo desta mágica é que 2 é raiz primitiva módulo 5 , que conceituaremos mais tarde.

Vamos exemplificar este truque. Imaginamos que a pessoa multiplique 15 fatores de 2 , ou seja, $2^{15}=32768$, e informe ao mágico, dizendo que o resto da divisão por 5 é 3 e a potência tem 5 algarismos. Com estas informações o mágico revela o número 32768.

O mágico descobriu o número fazendo as seguintes operações: Como o resto da divisão por 5 é 3 e a menor potência de 2 que deixa resto 3 quando dividido por 5 é o número $8, \log$ e ele fez $8 \cdot 16=128$, que é a segunda potência de 2 que deixa resto 3 quando dividido por 5 , mas esta só tem três algarismos. Ele multiplica novamente o resultado por $16,8 \cdot 16 \cdot 16=2048$, este número é a terceira potência de 2 que deixa resto 3 quando dividido por 5, mas ela só tem 4 algarismos. Ele multiplica novamente por $16,8 \cdot 16 \cdot 16 \cdot 16=32768$. Como 32768 tem 5 algarismos e é uma potência de 2 , logo é o número procurado.

Para realizar este truque, o mágico pode utilizar uma calculadora ou pode encontrar o produto utilizando o algoritmo da multiplicação, mas para deixar a plateia mais impressionada, é bom que ele decore as primeiras potências de base 16 , ou seja, $16^{1}=16 ; 16^{2}=256 ; 16^{3}=$ 4096 e $16^{4}=65536$, pois podemos perceber, utilizando o exemplo acima, se ele soubesse o resultado de $16^{3}$, basta agora multiplicar por 8, que encontrará o resultado.

Vamos mostrar explicar a mágica. Iniciaremos a explicação de que vem a ser uma raiz primitiva módulo um número primo, sem muito formalismo, utilizando alguns exemplos.

Temos que $2^{1}=2$ e 2 dividido por 5 deixa resto 2; $2^{2}=4$ e 4 dividido por 5 deixa resto $4 ; 2^{3}=8$ e 8 dividido por 5 deixa resto $3 ; 2^{4}=16$ e 16 dividido por 5 deixa resto 1 . Podemos observar que somente $2^{4}$ deixou resto 1 , quando dividido por 5 . Quando isso acontece somente no expoente $p-1$, com $p$ primo e o expoente $i$, com $1 \leq i \leq p-1$, dizemos que a base da potência é raiz primitiva módulo número primo, ou seja, neste caso 2 é raiz primitiva módulo 5 . Observe que 3 também é raiz primitiva módulo 5 , pois $3^{1}=3$ e 3 dividido por 5 deixa resto $3 ; 3^{2}=9$ e 9 dividido por 5 deixa resto 4 ; $3^{3}=27$ e 27 dividido por 5 deixa resto $2 ; 3^{4}=81$ e 81 dividido por 5 deixa resto 1 . Já o número 4 não é raiz primitiva módulo 5 , pois $4^{2}=16$ e 16 dividido por 5 deixa resto 1 , deixando resto 1 antes do expoente $p-1$, que neste caso é $5-1=4$.

Os restos das divisões das potências das raízes primitivas por $p$ geram conjuntos cíclicos, com $p-1$ elementos, ou seja, o conjunto dos restos da divisão da potência pelo primo, veja a figura 10 .

\begin{tabular}{|c|c|}
\hline$n$ & Resto de $n \div 5$ \\
\hline $2^{1}=2$ & 2 \\
\hline $2^{2}=4$ & 4 \\
\hline $2^{3}=8$ & 3 \\
\hline $2^{4}=16$ & 1 \\
\hline $2^{5}=32$ & 2 \\
\hline $2^{6}=64$ & 4 \\
\hline $2^{7}=128$ & 3 \\
\hline $2^{8}=256$ & 1 \\
\hline$\vdots$ & $\vdots$ \\
\hline
\end{tabular}

Figura 10: Restos das divisões das potências de base 2 por 5.

A partir dessas informações, observamos que existe uma relação biunívoca das potências de base 2 , com a mesma quantidade de algarismos, com o resto da divisão por 5, ou seja, quando o pessoa informa o resto 
da divisão para o mágico e a quantidade de algarismos, logo só existe uma potência que está associado a ele. Podemos garantir esta afirmação observando a tabela acima, por exemplo: $2^{1}$ deixa resto 2 , a próxima potência que deixa resto 2 é $2^{5}$, que é 16 vezes maior que $2^{1}$. Para garantirmos o aumento de 1 algarismo em um número, temos que multiplicá-lo no mínimo por 10. Como $16>10$, logo garantimos.

Podemos realizar variações desse truque. Por exemplo, em vez de utilizarmos base 2 podemos utilizar base 3 , já que 3 também é raiz primitiva módulo 5 . Podemos mudar o número primo, por exemplo, em vez de usar o 5 , usar 7 como módulo e usarmos 3 como base, já que 3 é raiz primitiva módulo 7 , verifique!

Pudemos perceber que este truque despertou interesse dos alunos pelas potências e também favoreceu ao aprendizado das multiplicações e divisões. É uma mágica para estimular e aperfeiçoar o cálculo mental.

\subsubsection{Adivinhação quinária}

Desenvolvemos este truque com propósito de estimular a divisão e multiplicação de números inteiros de 1 até 5 , sendo que por 5 aparece na maioria das vezes.

Peça a pessoa que pense em um número de 10 até 1000, e realize várias divisões sucessivas por 5, informando o resto das divisões e o último quociente encontrado, quando não conseguir mais dividir por 5 , ao mágico. O mágico de posse dos restos e do último resultado divulga o número pensado pela pessoa. Vamos utilizar um exemplo para mostrar o truque.

Imaginamos que a pessoa pense em 352, informa o resto 2 ao mágico e divide 350 por 5, encontrando 70 . Segue, informando o resto 0 ao mágico e divide 70 por 5 , encontrando 14. Informa o resto 4 e o último quociente 2 , ao mágico, já que não consegue dividir 2 por 5 . De posse das informações o mágico divulga o resultado.

Para desvendar o número, o mágico escreve o número desconhecido em base 5, utilizando os restos e o último resultado informados, ou seja, os algarismos que ele tem em posse é exatamente o número escrito em base cinco: $[2402]_{5}=[352]_{10}, \operatorname{logo}$ basta que ele faça a transformação inversa, da base cinco para a base 10, desta forma:

$$
[2402]_{5}=\left[2 \cdot 5^{3}+4 \cdot 5^{2}+0 \cdot 5^{1}+2 \cdot 5^{0}\right]_{10}=352 .
$$

Este truque pode ser estendido para outras bases, como binária e terciária, a fim de trabalhar o cálculo mental das operações básicas da Matemática. Achamos que os currículos de Matemática do ensino fundamental deveriam abordar e estimular atividades com outros sistemas de numeração, com bases diferentes da base decimal.

\section{Planos de Aula}

\subsection{Plano de aula sobre multiplicação de nú- meros inteiros: Conhecer e utilizar o mé- todo de multiplicação egípcia}

Seguem dois planos de aula abordados nas aplicações do trabalho.

\section{Objetivo:}

Construir e reforçar o conceito de multiplicação, bem como o algoritmo do produto por números inteiros, propondo um algoritmo diferente do tradicional que adota a base 10, utilizado hoje em dia na maioria das escolas brasileiras.

\section{Público Alvo:}

Alunos do $2^{\circ}$ semestre do $2^{\circ}$ segmento da EJA do CPP-DF (Centro de Progressão Penitenciária do Distrito Federal).

\section{Metodologia:}

Aplicar o questionário inicial ao aluno com enunciados de problemas cujas respostas são obtidas através da utilização da multiplicação de números inteiros, solicitado que resolvam os problemas com a estratégia que cada um conheça. Duração: 30 minutos.

Realizar as seguintes mágicas: Descobrir a peça de dominó que a pessoa está pensando, e adivinhando a soma de 10 números. Duração: 30 minutos.

Apresentar e resolver exemplos de multiplicações de números inteiros utilizando as técnicas tradicional e egípcia. Duração: 1 hora e 30 minutos.

Aplicar atividade para ser feita pelo aluno, utilizando o método de multiplicação egípcia, com intervenção do professor posteriormente a tentativa do aluno. Duração: 1 hora.

Desvendar as mágicas utilizando as operações de soma, subtração e multiplicação de números inteiros. Duração: 30 minutos.

Realizar o jogo do Hex multiplicativo. Duração: 1 hora.

Aplicar um segundo questionário. Este questionário tem os mesmos cálculos do primeiro, mas com histórias diferentes. Desta forma, teremos como investigar e analisar a evolução dos alunos. Duração: 30 minutos.

Duração total prevista: 5 horas 30 minutos. 


\subsection{Plano de aula sobre divisão de números inteiros: Conhecer e utilizar o método de divisão egípcia}

\section{Objetivo:}

Construir e reforçar o algoritmo da divisão de números inteiros propondo um algoritmo diferente do tradicional que adota a base 10, utilizado hoje em dia na maioria das escolas brasileiras.

\section{Público Alvo:}

Alunos do $2^{o}$ semestre do $2^{\circ}$ segmento da EJA do CPP-DF.

\section{Metodologia:}

Aplicar um questionário, ao aluno com enunciados de problemas cujas respostas são obtidas através da utilização da divisão de números inteiros, solicitado que resolvam os problemas com a estratégia que cada um conheça. Duração: 35 minutos.

Realizar as seguintes mágicas: Adivinhar o país, o animal e a cor que a pessoa está pensando e adivinhar o dia da semana em que a pessoa nasceu. Duração: 40 minutos.

Apresentar e resolver exemplos utilizando os métodos tradicionais e egípcio. Duração: 1 hora e 30 minutos.

Aplicar atividade para ser feita pelo aluno, utilizando o métodos de divisãos egípcia com intervenção do professor sempre que necessário. Duração: 1 hora.

Desvendar as mágicas utilizando as operações de soma, subtração e multiplicação e divisão de números inteiros. Duração: 40 minutos.

Realizar o jogo do Nim. Duração: 1 hora.

Aplicar o segundo questionário. Este questionário tem os mesmos cálculos do primeiro questionário, mas com histórias diferentes. Desta forma, teremos como investigar e analisar a evolução do aluno. Duração: 35 minutos.

Duração total prevista: 6 horas.

\section{Resultados}

Este item faz uma análise dos questionários aplicados sobre multiplicação e divisão de números inteiros positivos. Além disso, analisamos o perfil social dos alunos envolvidos.

\subsection{Perfil dos alunos do $2^{\circ}$ semestre do $2^{\circ}$ segmento do CPP - $2^{\circ}$ semestre de 2014}

Foi aplicado um questionário social com o intuito de conhecer o público que realizaremos este trabalho. 14 alunos preencheram o questionário, com idades mínima de 20 anos e máxima de 56 anos, com média de 35,8 anos e desvio padrão de 11,7 anos. A figura 11 mostra a faixa etária dos alunos.

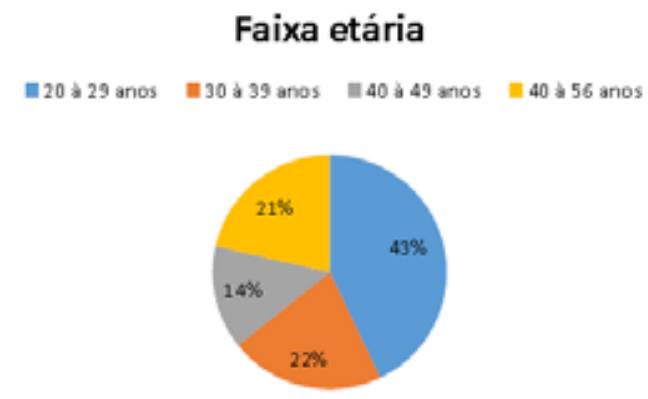

Figura 11: Faixa etária dos alunos.

Em relação ao estado civil, a maioria tem uma união estável, conforme a figura 12.

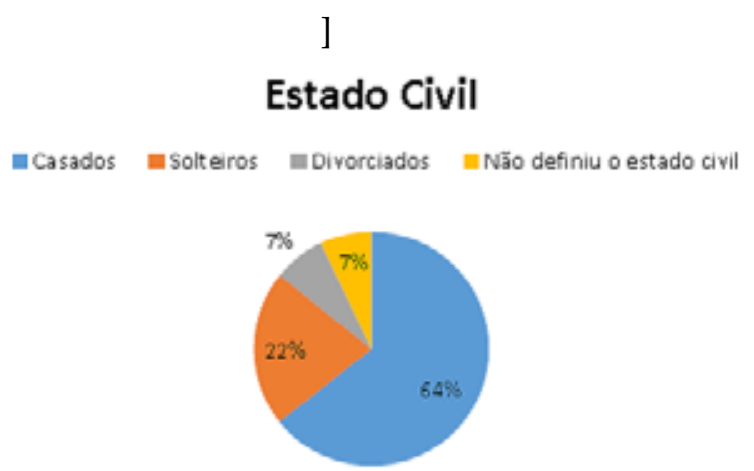

Figura 12: Estado civil dos alunos.

A maioria tem um ou dois filhos. Em média são 2,1 filhos por aluno conforme figura 13.

\section{Quantidades de filhos}

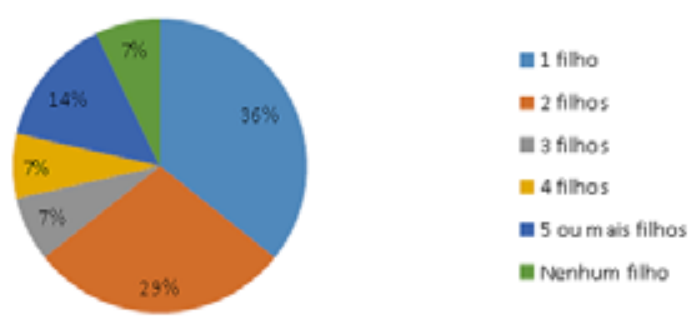

Figura 13: Quantidade de filhos dos alunos.

A respeito da interrupção dos estudos antes de entrarem no presídio, 92,9\% afirmam que em uma fase de sua vida tiveram que interromper seus estudos por algum motivo. 
A maioria dos alunos tiveram que interromper seus estudos na faixa de 15 e 17 anos, como podemos ver na figura 14 .

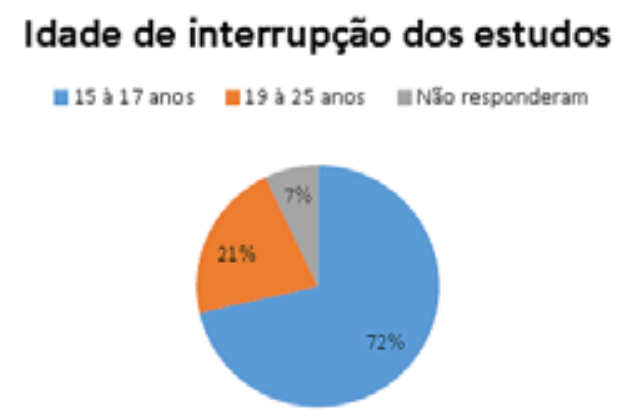

Figura 14: Idade em que os alunos interromperam seus estudos.

Todos os alunos afirmaram que gostam de estudar e $64,3 \%$ trabalham durante o dia. 64,3\% desejam estudar até formar em um curso superior; $21,4 \%$ desejam estudar até o ensino médio; $7,1 \%$ querem fazer apenas o ensino fundamental e apenas 7,1\% querem fazer uma pós-graduação.

Dentre os principais estímulos para os internos estarem estudando no presídio, em primeiro lugar é para conseguir um bom emprego e melhorar sua vida. E também pela a remição pelo estudo, para aprender coisas novas e para não ficar junto, neste período, com outros presos.

Analisando os alunos que estão estudando pela primeira vez dentro do presídio, existem alunos que estão fora de uma sala de aula há 39 anos. A média do tempo que estão fora da sala de aula é 15,7 anos com desvio padrão de 12,6 anos.

Veja na figura 15 os principais motivos para interrupção de seus estudos.

\section{Motivo de interrupção dos estudos}

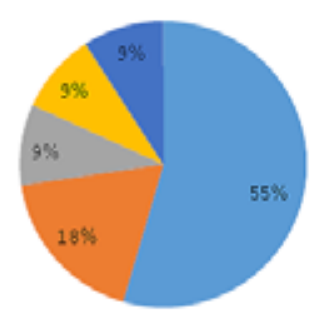

Eelo trabalho

absinteresse

wuso de Drogas

in Preso

a separaçăo dos pais

Figura 15: Motivo dos alunos pela interrupção dos estudos.

Percebemos que estes dois últimos motivos estão relacionados com o crime, ou seja, apenas 18,2\% alegam ter parado de estudar pelo envolvimento com o crime.
E ainda, pelo questionário social, notamos que a maior parte desses alunos teve algum tipo de motivo especial para abandonarem a escola, principalmente tendo que optarem pelo trabalho à escola. São pessoas que ficaram muito tempo sem estudar, em média 15,7 anos. Devido a esse grande tempo fora de uma sala de aula, o retorno não é fácil, temos que elaborar estratégias diferentes dos métodos tradicionais, pois estes não foram eficientes para eles em sua correta idade escolar, a fim de despertar o interesse do aluno pela escola e pela disciplina de Matemática. São alunos que têm em média 35,8 anos de idade, a maioria desses alunos trabalham durante o dia em serviços braçais devido ao baixo nível de escolaridade, chegando exaustos em sala de aula, alguns costumam dormir durante as aulas. Eles não reservam nenhum tempo adicional para o estudo fora da sala de aula. A maioria deles são casados, com filhos e têm saída para ver a família de 15 em 15 dias, e dizem que quando vão em casa nem lembra que existem escola e presídio. Querem aproveitar todo o tempo com a família, logo temos que trabalhar todo o conteúdo em sala de aula, não aplicando nada para fazer fora da escola.

Percebemos também que poucos têm oportunidade de estudar dentro do sistema penitenciário, ou seja, em relação a esta turma, apenas 35,7\% tiveram contado com a escola antes desse semestre, e a maioria que teve contato anteriormente, foi por um curto período.

\subsection{Aplicação e análise do plano de aula so- bre multiplicação de números inteiros}

Em relação a mágica da pedra de dominó, os alunos ficaram impressionados querendo que o professor revelasse-a. Pequena parte da sala teve um pouco de dificuldade de realizar os comandos da mágica, mas com a intervenção do professor resolveu esta dificuldade. Alguns tentaram desvendar a mágica, mas sem sucesso.

Os alunos acharam que a mágica da soma de 10 números foi mais interessante do que a da pedra de dominó e mais fácil de compreender os comandos. Alguns fizeram sequências diferentes em seus cadernos e mostraram os números ao professor que imediatamente dava o resultado da soma dos 10 números, cujo valor correto era verificado na calculadora.

Percebemos que ao utilizarmos $\mathrm{O}$ jogo Hex multiplicativo em sala de aula, os alunos tiveram que realizar várias multiplicações. Eles desenvolveram as operações de forma divertida e descontraída, não observamos desinteresse, por parte dos alunos, em realizá-las, fizeram de uma forma prazerosa e sem imposição. Portanto, devemos reservar um espaço em nossas aulas de Matemáticas para atividades lúdicas, fugindo algumas vezes das aulas tradicionais, pois também podemos aprendendo de forma divertida. 
Em relação aos exercícios propostos pelo professor para serem resolvidos utilizando o algorítmo egípcio, houve um bom resultado, pois foi a primeira vez que estes alunos tiveram contato com outro algoritmo para realizar multiplicações de números inteiros positivos. Grande parte da turma conseguiu resolver os 6 exercícios sem muita dificuldade. Dos que erraram 1 exercício, pode-se perceber que foi por falta de atenção. As dificuldades ocorreram por falta de pré-requisitos em relação a soma e multiplicação por 2.

Analisando os dados obtidos do primeiro questionário, a média do número de acertos foi de 2,4 questões por aluno; com desvio padrão de 0,7; valor mínimo de acertos 1 e máximo de 4 .

Analisando os dados do segundo questionário, a média do número de acertos foi de 3 questões por aluno; com desvio padrão de 1,2; valor mínimo de acertos 0 e máximo de 5 .

Observamos que a turma teve uma evolução do primeiro para o segundo questionário, no primeiro questionário teve uma média de questões certas de 2,4, enquanto no segundo foi de 3,0. Lembrando que nem todos os alunos participaram dos três encontros. Tivemos 9 alunos que participaram dos três encontros, 5 que participaram de 2 encontros e 5 que participaram apenas de um encontro.

Consideramos o segundo encontro como um dos mais importantes, pois nele foram abortados exemplos de multiplicação tradicional e egípcia e posteriormente exercícios realizados pelos alunos. Analisando somente os alunos que participaram de pelo menos dois encontros e que participaram do segundo encontro, tem-se uma média de questões certas de 3,2, ou seja, melhorando a média anterior, que era de 3,0.

Observamos em um aluno da turma, que participou dos três encontros e utilizou a multiplicação egípcia para resolve os exercícios propostos, que o mesmo não acertou nenhuma questão do segundo questionário. Percebemos que ele começou o algoritmo da multiplicação egípcia de forma equivocada, preenchendo a tabela com o valor do fator duplicado já na primeira casa, em vez de colocar somente na segunda, consequentemente errou todas as questões. Se desconsiderá-lo da análise, a média das questões certas dos alunos que participaram de pelo menos dois encontros e que participaram do segundo encontro sobe para 3,6.

O método egípcio foi bem aceito pelos alunos, por ser agradável de ser trabalhado. Depois de certo tempo trabalhando com o método egípcio, o aluno desenvolve habilidade de duplicar números inteiros utilizando diversas estratégias, diminuindo o erro nas multiplicações.

Percebemos que o método egípcio tem que ser apresentado com um tempo maior para sua melhor fixação. Observamos também que quando o aluno sabe a tabuada da multiplicação, o mais viável e mais ágil continua sendo o algoritmo tradicional.

Alguns alunos disseram que daqui para frente só iriam resolver multiplicações utilizando o método egípcio, devido à dificuldade em decorar a tabuada.

Percebemos que ao utilizarmos estes procedimentos adotados no plano de aula, como mágicas, novo algoritmo para multiplicação de números inteiros e jogos, os alunos foram muito participativos, menos dispersos, melhorando sua concentração e fazendo críticas. A aula ficou bem diversificada, dinâmica e atrativa, mas ao mesmo tempo não se perdeu o foco do conhecimento e da aprendizagem. É razoável inferir sempre que possível em nossas aulas de Matemática devemos sair do tradicional e mostrar coisas novas, divertidas e interessantes que envolva a Matemática, para que o aluno desperte interesse por ela.

\subsection{Aplicação e análise do plano de aula so- bre divisão de números inteiros}

Os alunos acharam a mágica adivinhar o país, o animal e a cor que a pessoa está pensando muito interessante. Acharam o algoritmo da mágica fácil de manipular, pois as operações envolvidas são simples, logo irão conseguir realizá-las com outras pessoas, exercitando cálculos básicos da Matemática.

Eles ficaram bastante impressionados com a mágica de adivinhar o dia da semana que uma pessoa nasceu. Num primeiro momento eles acharam a mágica muito complicada. O professou explicou a eles que ela não era "trivial" e precisaria de um pouco de prática para realizá-la. A pedido dos alunos, construímos a tabela dos meses em conjunto. Eles gostaram muito dessa mágica e foram muitos participativos. Tal mágica é uma forma interessante e divertida para trabalharmos divisões entre números inteiros observando seus restos, também a fim de conceituar e fortalecer a definição de múltiplos e divisores de números inteiros.

Em relação ao algoritmo de divisão egípcia, apesar de estarem trabalhando com ele pela primeira vez, alguns alunos já disseram que ele é bem mais fácil que o tradicional.

Eles acharam o jogo de Nim muito interessante e se divertiram bastante. Muitos deles não sabiam nem o que eram múltiplos de um número inteiro e que resto de divisão era tão importante. Podemos perceber que a utilização desse jogo em nosso plano de aula foi de grande valia, pois deixa aulas mais descontraídas, divertidas e introduzem ou reforçam conceitos de múltiplos, restos e quocientes da divisão de números inteiros.

Analisando os exercícios aplicados com 5 questões com uma nota máxima 5 . Temos 4,2 de média de acertos com o desvio padrão de 0,6 , com nota mínima de 3,5 e máxima 5. Podemos observar que eles já dominam melhor o algoritmo egípcio, pois já tinham trabalhado 
com ele na multiplicação. Nas questões que erraram, percebemos que é por falta de atenção.

Notamos ainda uma evolução particular de três alunos, que tinham grandes dificuldades com cálculos básicos da Matemática. Tem um que diz que nunca tinha conseguido realizar operação de divisão e hoje consegue fazê-la utilizando o método egípcio. Outro diz que daqui pra frente só vai fazer através do método egípcio. É importante alertar aos alunos que o método egípcio é adicional para quem tem dificuldade com a tabuada, e pedir que busquem também a prática com o algoritmo tradicional. Também percebemos evolução em outro aluno: ele tinha dificuldades até para duplicar um número e hoje ele apresenta os exercícios de forma correta.

Analisando o resultado do primeiro questionário, temos média de acertos de 2,2 com desvio padrão de 1,3 , com nota mínima 0 ponto e máxima de 5 pontos. Podemos observar que a média de acertos está abaixo de $50 \%$ do total de pontos, ou seja, o algoritmo tradicional de divisão entre números inteiros é considerado muito mais difícil do que o da multiplicação, também podemos observar que $50 \%$ dos alunos acertaram no máximo 2 questões.

Em relação ao segundo questionário, praticamente todos os alunos utilizaram o algoritmo da divisão egípcia para resolver as questões, apenas um utilizou o tradicional para resolver apenas 1 questão.

Analisando o segundo questionário encontramos média de acertos de 3,5 com desvio padrão de 1,4, com nota mínima 0 ponto e máxima de 5 pontos.

Comparando os dois questionários, podemos observar que a nota média dos alunos passou de 2,2 para 3,5 . Obtivemos um aumento 59\% de acertos utilizando o algoritmo egípcio.

Se analisarmos somente os 9 alunos que participaram dos três encontros, a média de questões certas sobe para 4,1 com desvio padrão de 0,9 , nota mínima de 3 e máxima de 5. Acredito que esta melhora é devido à familiaridade com o algoritmo egípcio, pois já tínhamos trabalhado com ele na multiplicação de números inteiros, mostrando que ele é de fácil manipulação e assimilação. Ele deveria ser utilizado em séries iniciais do ensino fundamental, principalmente em turmas da EJA, como uma forma alternativa de divisão entre números inteiros positivos, pois encontramos muitos alunos em nossas salas de aula que têm bastante dificuldade com a tabuada e o algoritmo tradicional de divisão.

\section{Considerações Finais}

Com esse trabalho, utilizando a ludicidade, sobretudo, em se tratando de alunos inseridos em um sistema penitenciário, como formas alternativas para realizar multiplicações e divisões entre números inteiros, tru- ques matemáticos e jogos pedagógicos, constatamos que contribuímos com o processo de ensino e aprendizagem das operações de multiplicação e divisão de números inteiros positivos.

Os truques matemáticos, abordados no início de cada aula, serviram de forma eficiente para despertar o interesse dos alunos para o conteúdo que foi ministrado na aula. A partir dessa abordagem, percebemos que eles ficaram mais atentos e motivados a aprender.

As novas técnicas de multiplicações e divisões, que foram utilizadas nos planos de aulas, foram alternativas agradáveis para fugir dos algoritmos tradicionais, melhorando o aprendizado de muitos alunos que tinham dificuldade com estes algoritmos. Os que não tinham dificuldades aceitaram os novos algoritmos de forma curiosa e prazerosa, achando-os mais fáceis de manipular do que o método tradicional.

Os jogos pedagógicos, realizados ao final de cada aula, foram uma maneira eficiente de sistematização, importantes para o amadurecimento dos conceitos trabalhados anteriormente, pois a interação, motivação e o desafio contido no ato de jogar, levaram os alunos a trabalhar com as operações de multiplicações e divisões de números inteiros positivos de forma agradável, realizando-as fora do contexto de uma aula tradicional. Entendemos que o ato de jogar pode ser um grande aliado para o processo de ensino e aprendizagem. Percebemos que estes alunos necessitam de movimentação e interação para motivar sua permanência na escola e na sala de aula.

Como as aulas são longas, cerca de 2 horas e 30 minutos de duração, quando realizadas pelo método tradicional, podem se tornar monótonas e desmotivadoras, não sendo eficientes, portanto, deixa o público-alvo cansativo, desmotivado e sem interesse. Os planos de aula deste trabalho foram eficientes, pois mostramos que as aulas tornaram-se mais motivadoras e interessantes, deixando os alunos sempre atentos durante todo período.

Percebemos que seria melhor ter destinado um tempo maior para a manipulação dos novos algoritmos de multiplicação e divisão entre números inteiros, para que eles fossem bem solidificados. Apesar da aula ter ficado bem diversificada e dinâmica, tínhamos que agilizar as atividades para cumprir com o tempo previsto. Deixamos, portanto, a sugestão de aumento de tempo em cada atividade.

Com a aplicação de questionários, antes e depois de cada plano de aula, verificamos uma evolução significativa em relação ao aprendizado dos alunos, principalmente nas operações de divisões entre números inteiros.

A taxa de evasão escolar de internos do regime semiaberto é grande. Os internos mudam do regime fechado para o semiaberto e matriculam na escola, mas depois 
de alguns dias, quando começam a trabalhar, alegam cansaço e abandonam a escola. Observamos que utilizando estas estratégias diminuiu consideravelmente a taxa de evasão escolar e melhoraram as frequências dos alunos desta turma. Tínhamos 15 alunos matriculados neste período, quando foi realizado o plano de aula sobre divisão entre números inteiros, e uma média de 12 alunos por aula. Melhora significativa, comparando com outra turma de segundo segmento, que no mesmo período tinha 14 alunos matriculados, mas somente 6 eram frequentes.

Mostramos através desse trabalho que se abordarmos a Matemática, utilizando uma diversidade de ferramentas pedagógicas divertidas, de forma apropriada e relacionada com o conteúdo ministrado, podemos deixar as aulas de mais eficientes e ao mesmo tempo agradáveis.

No algoritmo do método quinário, a escolha da base 5 em vez da base 2, para realizar tanto a multiplicação e a divisão de números inteiros foi por perceber que utilizando a base 5, o algoritmo se reduz, pois o seu crescimento é bem superior a base 2, e multiplicar por 5 tem o mesmo nível de dificuldade que multiplicar por 2. Relembrando que para multiplicar um número por 5 basta acrescentar um zero a direita e encontrar a metade. E dividir por cinco, o oposto, dobra-se o número e retira o zero a direita. Podemos realizar diversas variações desse algoritmo. Por exemplo, em vez de utilizarmos base 5 podemos utilizar base 3 ou 7. É interesse notar que a escolha de uma base diferente da tradicional, que adota a base 10, não visa substituir o ensino da última nas escolas, mas sim complementar seu estudo, oferendo mais um sistema de contagem ao discente, que pode vir a ser útil quando o mesmo se deparar com situações que requerem agrupamentos em quantidades diferentes de múltiplos de 10.

Este trabalho pode servir como subsídios para que docentes da disciplina de Matemática, principalmente da educação de jovens e adultos, tenham oportunidade de repensar sua prática na sala de aula, elaborando planos de aulas mais eficientes, mas ao mesmo tempo agradáveis.

Os truques e jogos pedagógicos não irão substituir os métodos de ensino tradicionais, porém serão uma alternativa para reforçar os conceitos matemáticos ensinados ou até mesmo introduzir um conceito a ser ministrado.

Construímos algoritmos para realizar multiplicação e divisão entre números inteiros, jogos e truques, mas por um questão de tempo não conseguimos introduzilos nos planos de aulas que aplicamos. Eles estão no trabalho para consulta de profissionais da educação que desejam utilizá-los em seus planos de aulas, a fim de deixar suas aulas de Matemática agradáveis, divertidas e participativas.

\section{Referências}

EVES, H. (2011). Introdução à História da Matemática, $5^{\circ}$ edn. Editora da Unicamp, Campinas.

GRANDO, R. C. (2000). O conhecimento matemático e o uso de jogos na sala de aula. Tese de Doutorado, Unicamp, Faculdade de Educação, Campinas.

GUINTHER, A. (2009). Análise do desempenho de alunos do ensino fundamental em jogos matemáticos: reflexões sobre o uso da calculadora nas aulas de matemática. Dissertação de Mestrado, Pontifícia Universidade Católica de São Paulo, São Paulo.

HEFEZ, A. (2013). Aritmética, Coleção PROFMAT, $1^{\circ}$ edn. SBM.

SÁ, I. P. (2010). A Magia da Matemática, $3^{\circ}$ edn. Editora Ciência Moderna.

SAMPAIO, J. C., MALAGUTTI, P. L. A. (2006). Mágicas Matemática e Outros Mistérios, $1^{\circ}$ edn. Edufscar.

TORRES, J. D. S. (2013). Jogos de Matemática e de Raciocínio Lógico, $1^{\mathrm{O}}$ edn. Editora Vozes. 